\title{
The effect of surgical management of endometrioma on the IVF/ICSI outcomes when compared with no treatment? A systematic review and meta-analysis
}

\author{
M. Nickkho-Amiry ${ }^{1}$ (D) R. Savant ${ }^{2} \cdot$ K. Majumder $^{2} \cdot$ E. Edi-O'sagie $^{2} \cdot$ M. Akhtar $^{2}$
}

Received: 13 June 2017 / Accepted: 22 December 2017 / Published online: 17 January 2018

(c) The Author(s) 2018. This article is an open access publication

\begin{abstract}
Objective To assess the impact of surgical management of endometrioma on the outcome of assisted reproduction treatment (ART).

Design A systematic review and meta-analysis.

Setting Department of reproductive medicine at teaching university hospital, UK.

Patients Subfertile women with endometrioma undergoing ART.

Interventions Surgical removal of endometrioma or expectant management.

Main outcome measures Clinical pregnancy rate, pregnancy rate, live birth rate, number of oocytes retrieved and number of embryos available and ovarian response to gonadotrophins.

Results An extensive search of electronic databases for articles published from inception to September 2016 yielded 11 eligible studies for meta-analysis. Meta-analysis was conducted comparing surgery versus no treatment of endometrioma. There were no significant differences in pregnancy rate per cycle, clinical pregnancy rate and live birth rate between women who underwent surgery for endometrioma and those who did not.

Conclusion Current evidence suggests that women with endometriosis-related infertility have similar cycle outcomes to other patients going through ART. It is pertinent for clinicians to assess the risks of surgical intervention on ovarian reserve prior to initiating therapy.
\end{abstract}

Keywords Endometrioma $\cdot$ Surgery $\cdot$ ART $\cdot$ Pregnancy outcome

\section{Introduction}

Endometriosis is a chronic-debilitating disease that affects $5-10 \%$ of fertile women [1]. It is characterised by the presence of endometrial-like tissue (glands and stroma) outside the uterus, which induces a chronic inflammatory reaction, scar tissue, and adhesions that may distort a woman's pelvic anatomy [2]. Around 25-50\% of women with infertility may be affected by endometriosis, and $30-50 \%$ of women with endometriosis have infertility [3].

M. Nickkho-Amiry

mamiry@me.com

1 University Hospital of South Manchester, Southmoor Rd, Wythenshawe, Manchester M23 9LT, UK

2 Central Manchester Foundation Trust, Manchester, UK
Women with endometriosis often require assisted reproduction technology (ART) and the severity of endometriosis has been linked to ART outcome [4]. However, further research is necessary to understand this association. Multiple hypotheses have been suggested to explain the low fecundity observed with endometriosis. Most commonly, the association has been attributed to altered folliculogenesis resulting in reduced quality oocytes [5], mechanical interference with oocyte pickup and transportation [6], exposure to a hostile environment of macrophages, cytokines and vasoactive substances in the peritoneal fluid [7,8] and anatomical dysfunction of the fallopian tube and ovary [9].

An endometrioma is the formation of a cyst within the ovary with ectopic endometrial tissue lining [10, 11]. An endometrioma is one of the most common manifestations of endometriosis. Endometriomas are found in 17-44\% of patients with endometriosis [12]. The pathogenesis of an endometrioma is complex and different compared to that of 
other benign ovarian cysts. A majority of endometriomas are thought to be pseudocysts as described by Hughesdon rather than intra-ovarian cysts $[10,11]$.

Endometriomas are often associated with deep endometriosis and often do not respond well to medical therapy. Medical therapy may relieve the symptoms and improve pain or reduce the size of the cyst but does not improve infertility [13]. Therefore, the focus has been on surgical treatment in an attempt to improve fertility.

There has been much speculation as to the exact mechanism by which endometriomas cause infertility. Researchers have suggested that there is a decrease in ovarian reserve and follicular density in women with endometriomas possibly due to an increase in oxidative stress [14]. However, surgical resection of these cysts has been shown to further decrease ovarian reserve [13]. This highlights that there is much debate regarding the treatment of endometriomas, and uncertainty with regards to infertility, particularly in women who are undergoing assisted reproductive technology (ART).

The aim of this paper is to elucidate the effect of surgical management of ovarian endometriomas on fertility outcomes after ART.

\section{Materials and methods}

\section{Search strategy}

Related studies were identified after extensive search of PUBMED, Medline, EMBASE and Cochrane database from inception to September 2016. The following keywords and synonyms were used: 'endometrioma', 'cystectomy', 'IVF', ICSI', 'pregnancy'. The language of publication was restricted to English. The European Society of Human Reproduction and Embryology guidelines were also reviewed. International standard randomised controlled trial number registry was checked for any trials registered with them. The reference lists of all publications and reviews were hand-searched to identify missing relevant publications. Two authors (RS and MA) independently conducted the search, and reviewed titles, abstracts and full manuscripts. Each article was independently assessed for inclusion and exclusion criteria. The review was registered with PROSPERO: International prospective register of systematic reviews. The ID number is CRD42015023914.

\section{Study selection}

The studies that were included in the meta-analysis met the following criteria: (1) an original paper; (2) a study of ovarian endometrioma; (3) a clinical study (including randomised controlled trials, case-control, prospective and retrospective cohort studies) that assessed the association of ovarian response, oocyte quality, embryo quality and IVF outcome with ovarian endometrioma.

All controlled retrospective or prospective studies that studied the effect of surgery on endometrioma or aspiration of endometrioma on IVF/ICSI outcome and ovarian response to gonadotrophins and those with a defined comparison group were included in the review.

The major exclusion criteria were literature reviews, non-original articles; non-ovarian endometrioma; duplication of a previous publication; and women who did not receive intervention on the endometrioma and women who had received medical or surgical treatment of their ovarian endometrioma before IVF cycles.

The Preferred Reporting Items for Systematic Reviews and Meta-Analyses (PRISMA) checklist was used while writing this review (Fig. 1).

\section{Outcome measures}

The primary outcomes were live birth rate per cycle, clinical pregnancy rate per cycle (defined as visualisation of fetal heart activity on transvaginal ultrasound at $\geq 6$ week) and pregnancy rate (positive pregnancy test after ART).

Secondary measures included the ovarian response to gonadotropin stimulation by the total number of gonadotrophin ampoules required for ovarian stimulation, the peak E2 levels on the day of the hCG administration and the total number of oocytes retrieved with and number of embryos available for transfer.

\section{Statistical analysis}

Data analyses were carried out using RevMan, version 5.3 (Cochrane, Collaboration, Oxford, UK). Heterogeneity was evaluated graphically using forest plots and statistically using the $I 2$ statistic to quantify heterogeneity across studies. An $I 2>50 \%$ was considered to represent substantial heterogeneity between studies. A random-effect model was used for meta-analysis in cases of high heterogeneity, and a fixed- effect model was used in cases of low heterogeneity. Dichotomous outcome data were reported as odds ratios with 95\% confidence intervals (CI). Continuous data were synthesized using weighted means with $95 \% \mathrm{CI}$ for variables including number of gonadotrophin ampoules required for ovarian stimulation, the peak E2 level and the number of oocytes.

\section{Results}

The search strategy yielded 721 articles, 91 of these were relevant to our review. 48 of these studies were found to be potentially eligible. 
Fig. 1 Prisma flow diagram

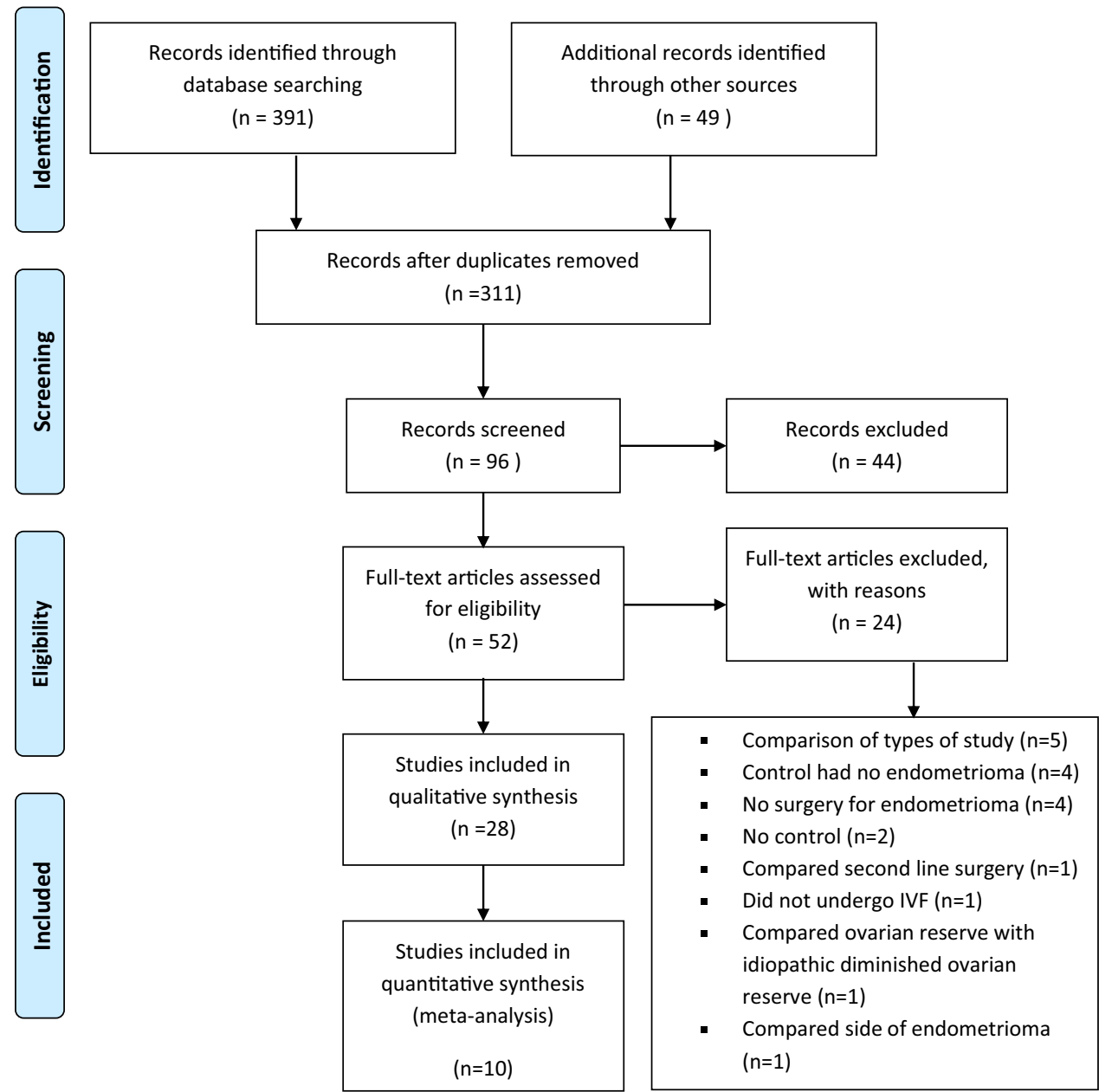

\section{Included studies}

The characteristics of the 28 studies included in the systematic review and classified according to their controls are presented in Table 1. The majority were retrospective case-control studies. Ten studies were included for quantitative synthesis that compared surgical treatment versus no treatment (meta-analysis, Fig. 1). There were two prospective cohort $[15,16]$ and three retrospective cohort studies [17-19]. Only one randomised control trial was available for study. Randomisation for aspiration of endometrioma was done in one study [15]. One prospective case-control study with randomisation for gonadotrophins was noted [20].

Laparoscopic excision of endometriomas by either ovarian cystectomy or stripping of the cyst wall was performed in the majority. Seven studies also involved laparotomies for endometrioma surgery [15, 18-23].

\section{Ovarian stimulation was with the long protocol in the majority of the cases}

The size of the endometriomas, the duration from surgery to IVF and the laterality of the cyst are documented in Table 1. The control group varied and this has been classified in Table 1. Seven studied used multiple control groups [15, 18, 19, 22, 24-26].

There was no significant difference between the study and the control group with regards to the patient characteristics and the other confounding factors.

We included a total of eleven studies in our meta-analysis. Ten studies compared surgical treatment for endometrioma with untreated endometrioma and four studies compared surgical treatment of endometrioma with aspiration of endometrioma. Among these, there were six retrospective case-control [19, 20, 26-29], two retrospective cohort [17, 


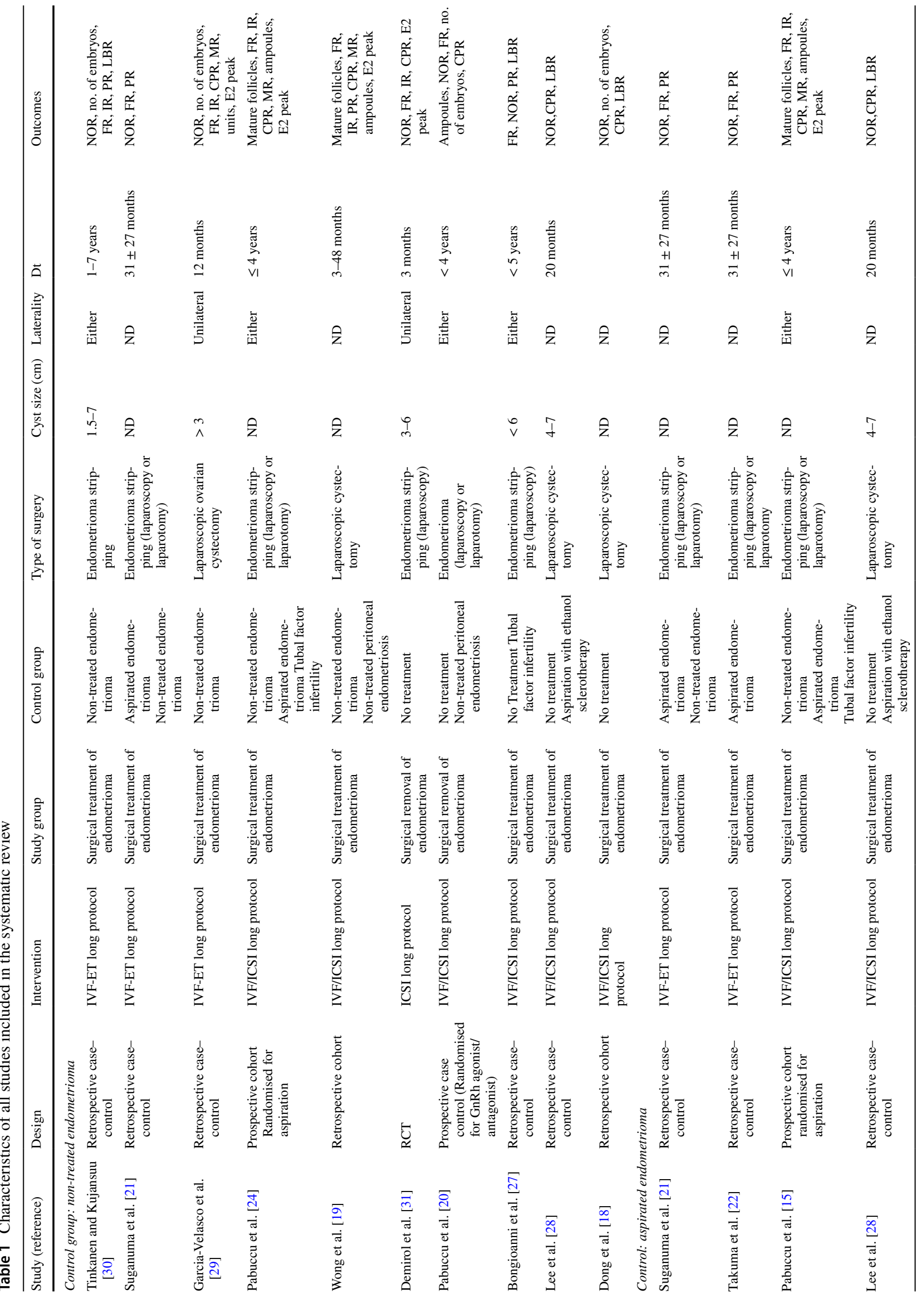




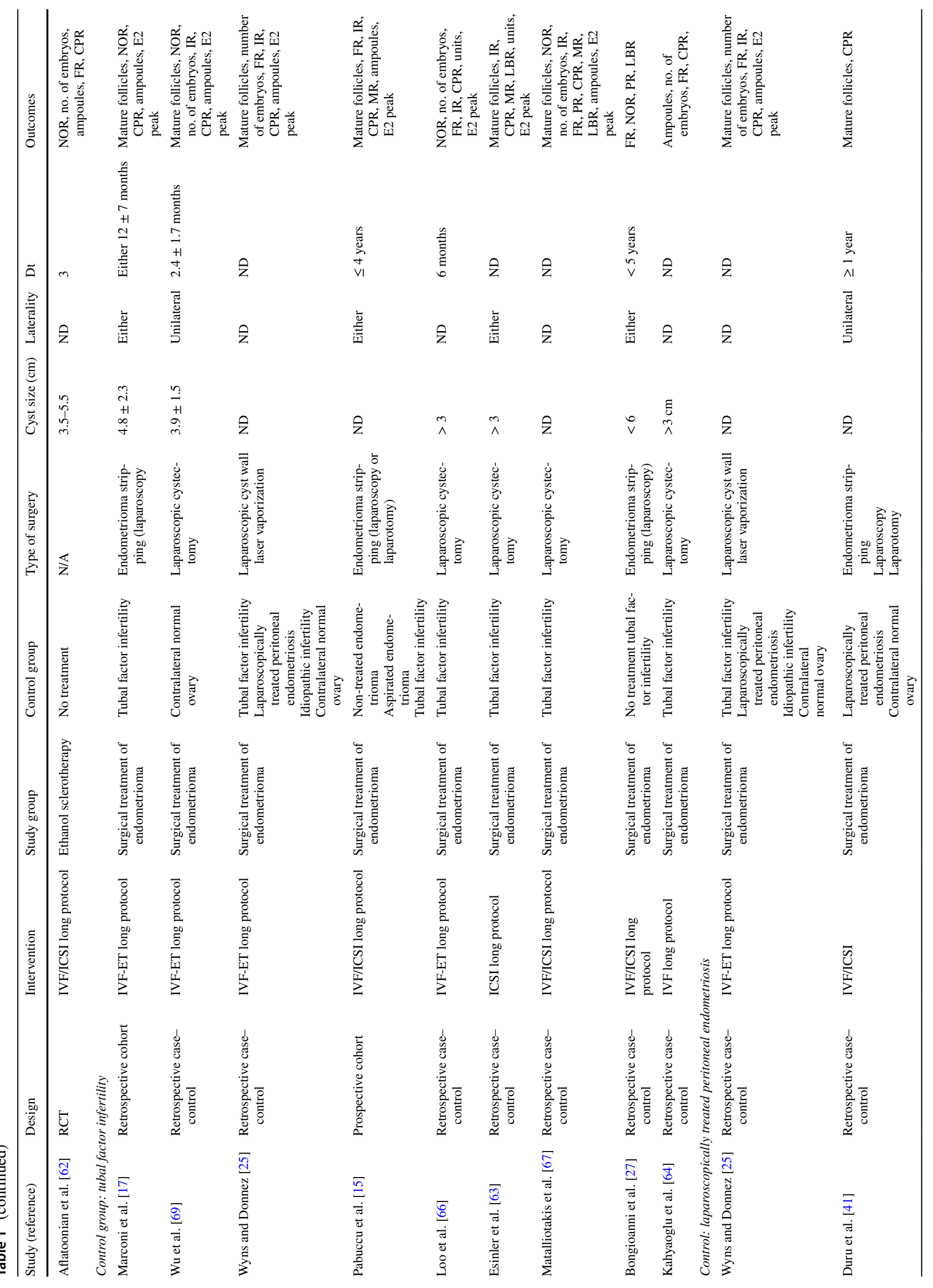




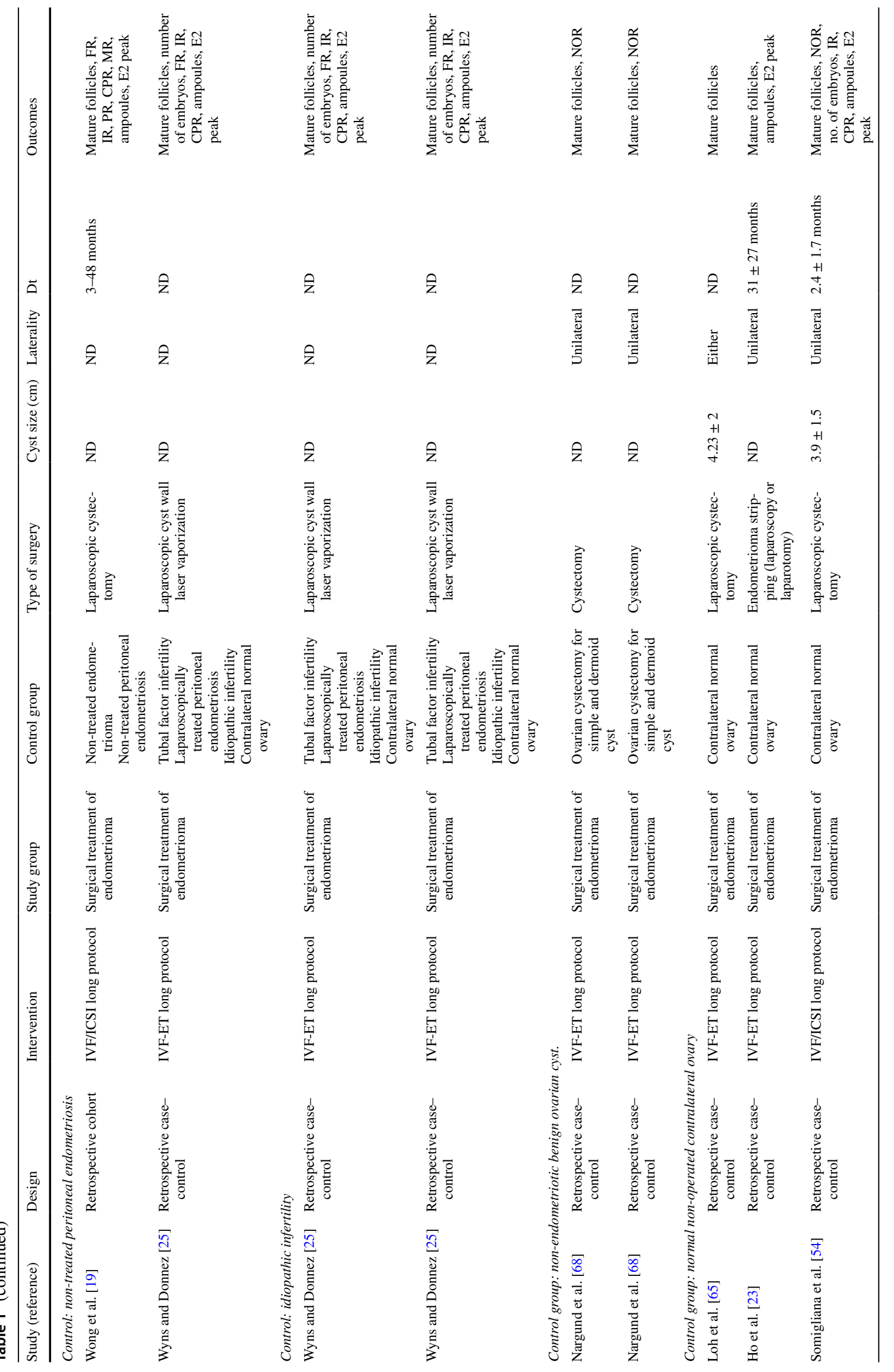




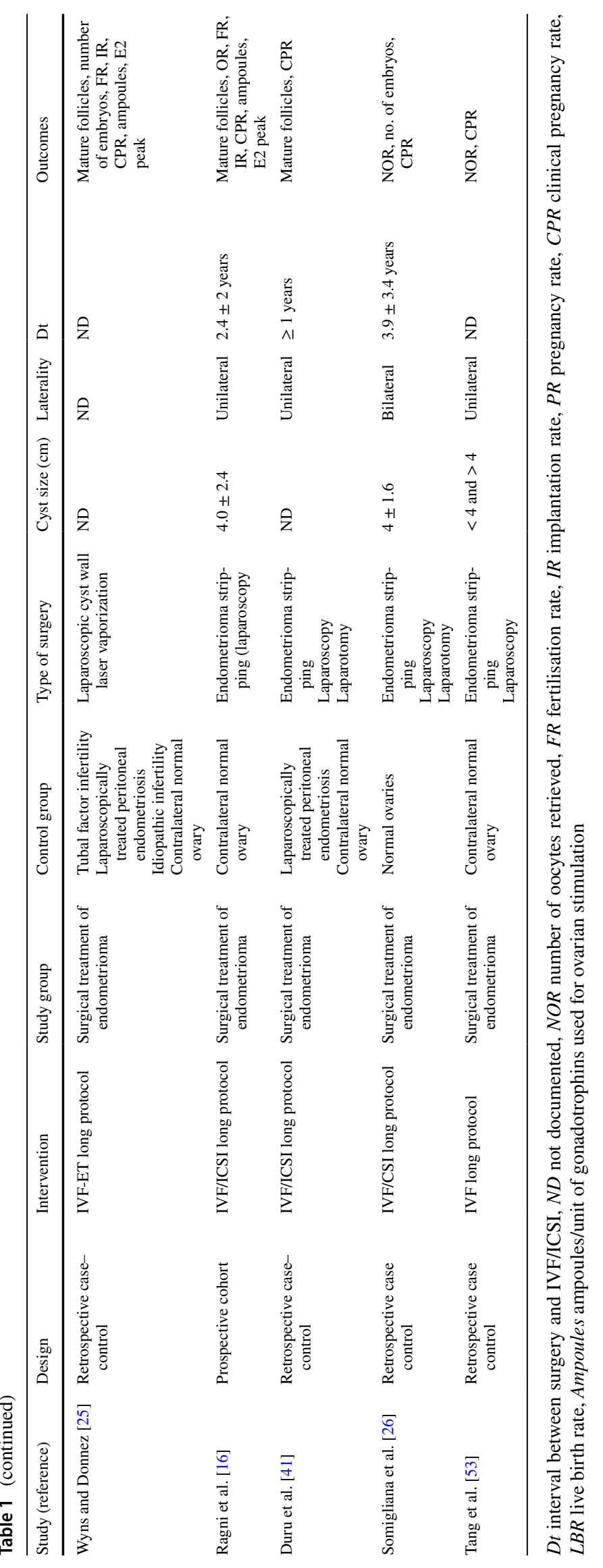


25] and one prospective case-control studies [18]. One randomised control trial [30] and one prospective cohort study with randomisation for aspiration of endometrioma [15] were studied.

The forest plots of the meta-analysis comparing surgical treatment with no treatment and surgical treatment with aspiration of endometrioma are presented in Table 2 and Fig. 2.

\section{Main outcomes}

Surgical treatment compared to no treatment.

There were ten studies that compared surgical treatment to no treatment included in this review. Meta-analysis of these results is as follows:

\section{Primary outcome}

Live birth rate.

Surgery for endometrioma showed to favour live birth rate per cycle, but this was not statistically significant [4 studies, OR 0.75 (95\% CI 0.54, 1.06)] (Fig. 2a1).

\section{Clinical pregnancy rate}

There were no significant differences in clinical pregnancy rate between women who underwent surgery for endometrioma and those who did not per cycle 1.08 [7 studies, OR 1.08 (95\% CI 0.80-1.45)] (Fig. 2a2).

\section{Pregnancy rate}

There were no significant differences in pregnancy rate per cycle between women who underwent surgery for endometrioma and those who did not [5 studies, OR 0.88 (95\% CI 0.60, 1.29)] (Fig. 2a3).

\section{Secondary outcomes}

Number of oocytes retrieved There was also no statistical difference in the number of oocytes retrieved [mean difference $-0.43(95 \% \mathrm{CI}-1.67,0.80)]$ and the total number of embryos created per cycle [mean difference 0.06 95\% CI -0.21 to 0.33$)$ ] in the group that underwent surgery for endometrioma compared to the control with no surgery (Fig. 2a5, a6).

Gonadotropin usage There was no difference in between gonadotrophin ampoules used per cycle [mean difference $1.31(95 \% \mathrm{CI}(-3.87,6.50)]$ and the total gonadotrophin dose per cycle [mean difference 244.81 (95\% CI - 525.43 to 1015.06)] between the two groups (Fig. 2a6, a7).

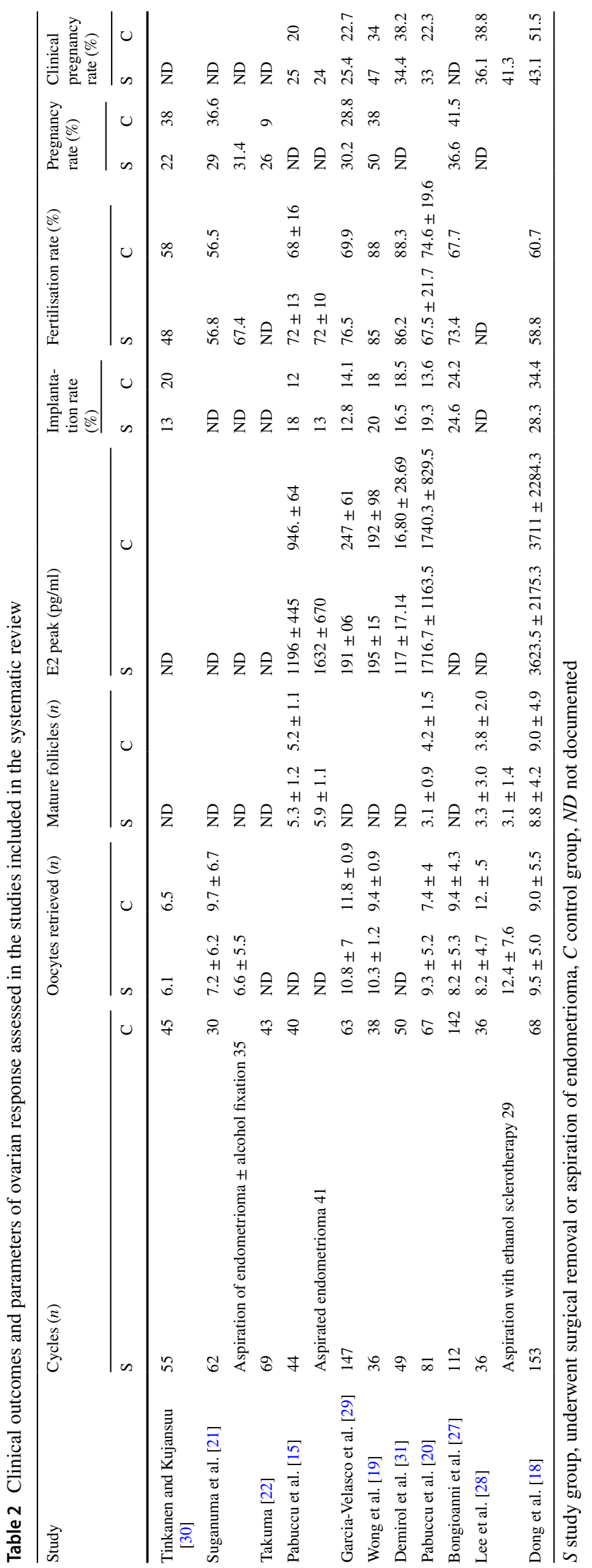


A Surgical treatment vs No treatment ( 10 studies)

1. Live birth rate / cycle

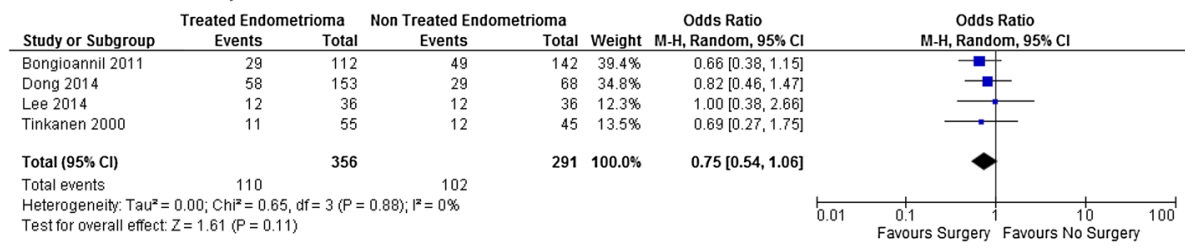

2. Clinical Pregnancy / cycle

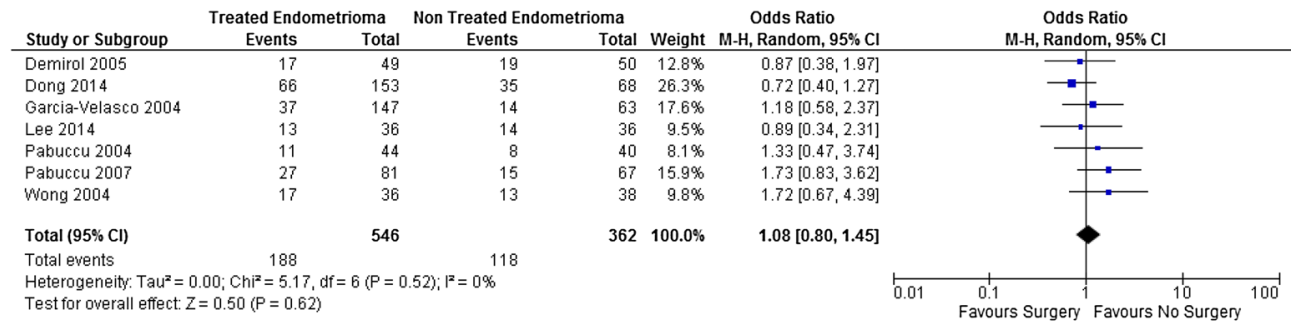

\section{Pregnancy/cycle}

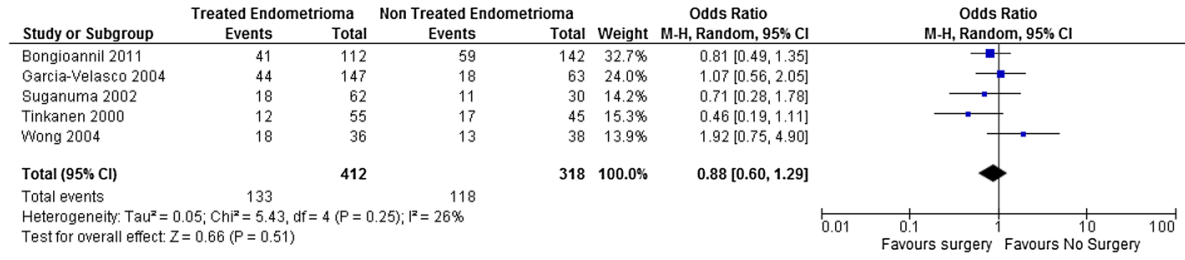

\section{Estradiol peak $(\mathrm{pg} / \mathrm{ml})$}

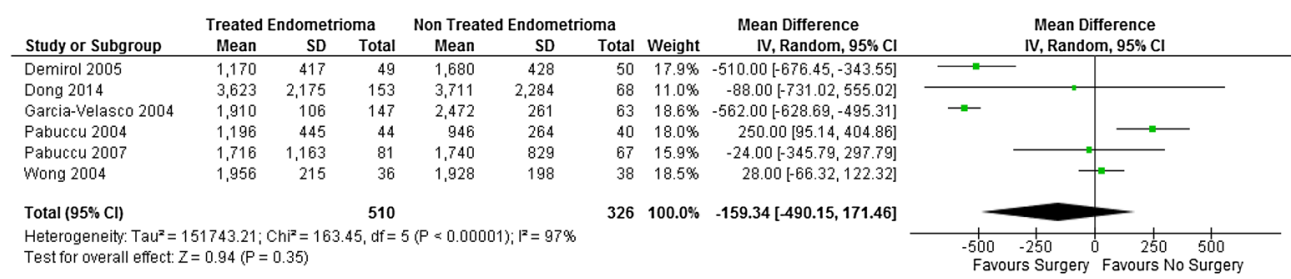

5. Total Oocytes retrieved/ cycle ( continuous data)

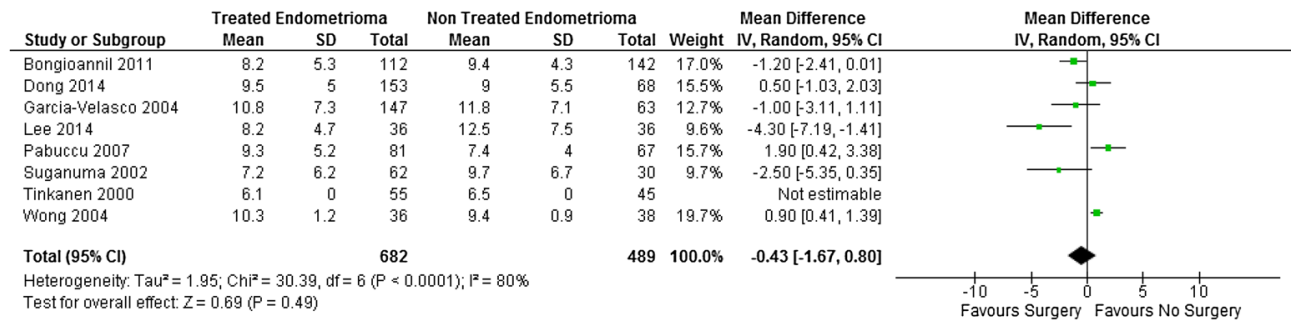

6. Total No of embryos created / cycle

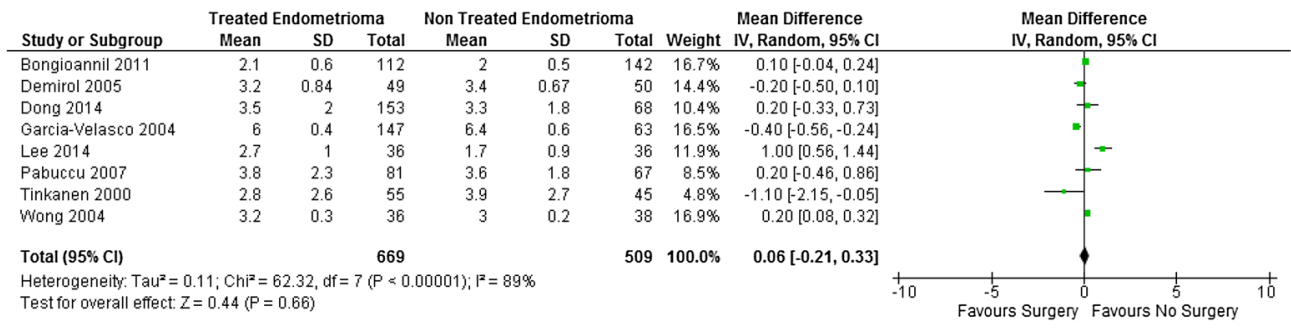


4 Fig. 2 Forest plots examining outcome measures. a Surgical treatment versus no treatment (10 studies). 1. Live birth rate/cycle. 2. Clinical pregnancy/cycle. 3. Pregnancy/cycle. 4. Estradiol peak (pg/ $\mathrm{ml})$. 5. Total oocytes retrieved/cycle (continuous data). 6. Total no. of embryos created/cycle. 7. Gonadotrophins ampoules/cycle. 8. Gonadotrophins total dose/cycle. b Surgical treatment versus aspiration (4 studies). 1. Pregnancy/cycle. 2. Clinical pregnancy/cycle

Estradiol peak during ART There was no difference in the estradiol peak in the two groups. (mean difference -159.349 (95\% CI - 490.15, 171.46)] (Fig. 2a4).

Surgical treatment compared to aspiration There were four studies included in the meta-analysis comparing surgical treatment with aspiration $[15,19,20,27]$.
There was no difference between the pregnancy rate per cycle [OR 1.66 (95\% CI 0.44, 6.26)] and clinical pregnancy rate per cycle [OR $0.92(95 \% \mathrm{CI}-1.43,1.95)$ ] between those women who underwent surgery for endometrioma and those who had aspiration of endometrioma (Fig. 2a1, b2). There were no live births reported.

\section{Excluded studies}

19 studies from the potentially eligible studies were excluded (see Table 3). Four studies were excluded as the control did not have endometrioma and two of the studies did not have a control. Four studies did not have surgery for endometriomas, five compared types of surgery and one compared second line surgery for endometriomas.

\section{Gonadotrohpin ampoules / cycle}

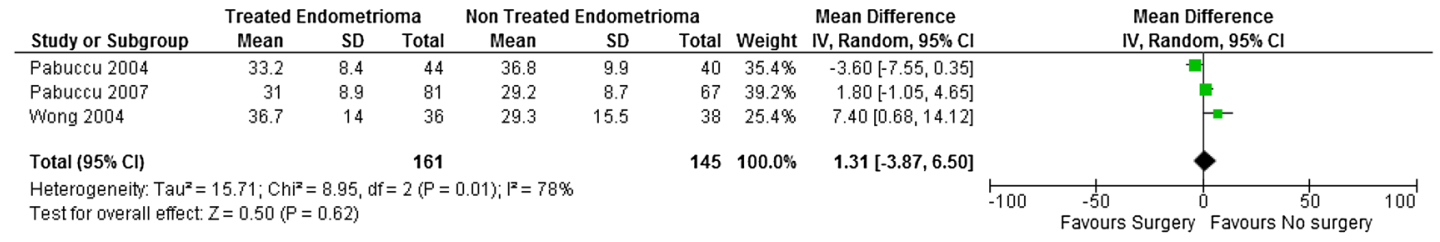

8. Gonadotrophins total dose /cycle

\begin{tabular}{|c|c|c|c|c|c|c|c|c|c|c|c|c|}
\hline \multirow[b]{2}{*}{ Study or Subgroup } & \multicolumn{3}{|c|}{ Treated Endometrioma } & \multicolumn{3}{|c|}{ Non Treated Endometrioma } & \multirow[b]{2}{*}{ Weight } & \multirow{2}{*}{$\begin{array}{l}\text { Mean Difference } \\
\text { IV, Random, } 95 \% \mathrm{CI}\end{array}$} & \multirow{2}{*}{\multicolumn{4}{|c|}{$\begin{array}{l}\text { Mean Difference } \\
\text { IV, Random, } 95 \% \mathrm{Cl}\end{array}$}} \\
\hline & Mean & SD & Total & Mean & SD & Total & & & & & & \\
\hline Dong 2014 & 2,954 & 1,216 & 153 & $3,122.8$ & 1,118 & 68 & $32.7 \%$ & $-168.80[-497.03,159.43]$ & & & & \\
\hline Lee 2014 & 1,940 & 407 & 36 & 2,015 & 673 & 36 & $33.4 \%$ & $-75.00[-331.92,181.92]$ & & & & \\
\hline Total $(95 \% \mathrm{Cl})$ & & & 356 & & & 291 & $100.0 \%$ & $244.81[-525.43,1015.06]$ & & & & \\
\hline \multicolumn{9}{|c|}{$\begin{array}{l}\text { Heterogeneity: } \operatorname{Tau}^{2}=444694.57 ; \mathrm{Chi}^{2}=53.11, \mathrm{df}=2(\mathrm{P}<0.00001) ; \mathrm{I}^{2}=96 \% \\
\text { Test for overall effect: } Z=0.62(\mathrm{P}=0.53)\end{array}$} & 0 & $\begin{array}{l}-500 \\
\text { Favours Surgery }\end{array}$ & Favours $\mathrm{N}$ & $\begin{array}{ll}500 & 1000 \\
\text { JoSurgery } & \end{array}$ \\
\hline
\end{tabular}

B Surgical treatment vs Aspiration ( 4 studies)

1. Pregnancy / cycle

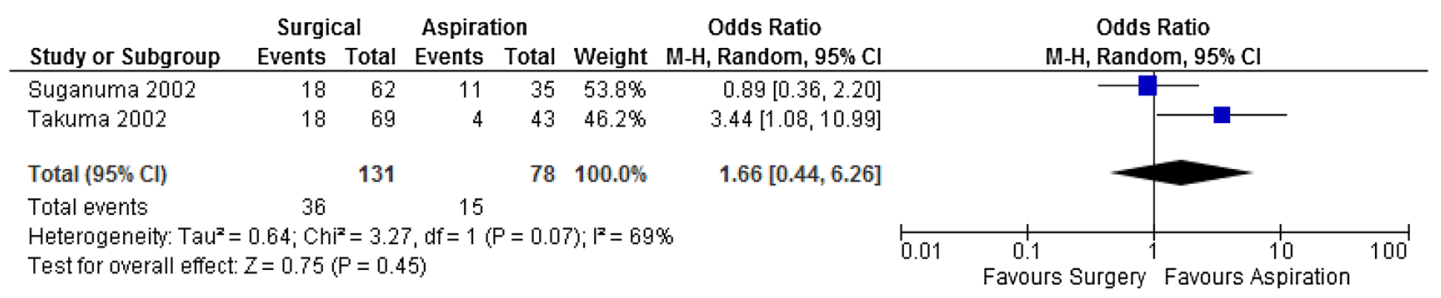

2. Clinical Pregnancy / cycle

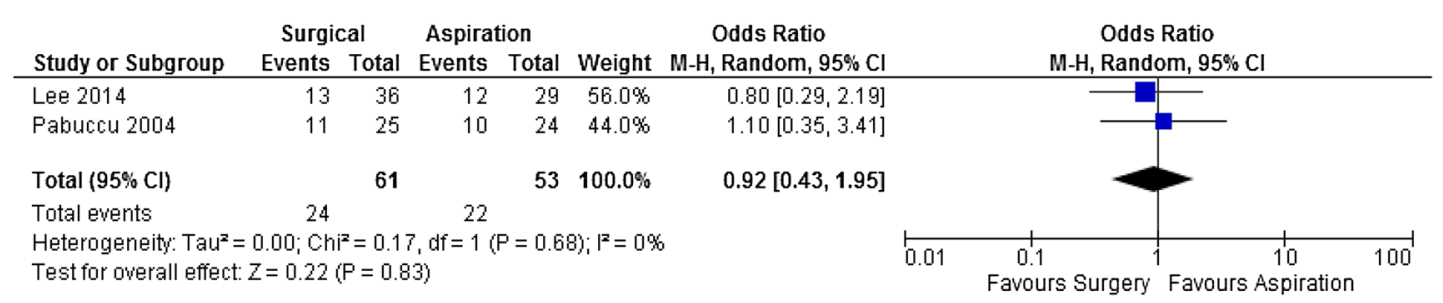

Fig. 2 (continued) 
Table 3 Reason for exclusion of study

\begin{tabular}{ll}
\hline Reason for exclusion & References \\
\hline Control had no endometrioma & {$[26],[31-34]$} \\
No control & {$[35,36]$} \\
No surgery for endometrioma & {$[37-40]$} \\
Types of surgery & {$[41-45]$} \\
Second-line surgery & {$[46]$} \\
Side of endometrioma & {$[47]$} \\
Did not undergo IVF & {$[48]$} \\
Compared ovarian reserve with idiopathic diminished & {$[49]$} \\
ovarian reserve & \\
\hline
\end{tabular}

One studies compared the effect of the side of endometriomas, the subjects did not undergo IVF in another and one studied reduced ovarian reserve in comparison to idiopathic diminished ovarian reserve.

\section{Discussion}

The aim of this systematic review and meta-analysis was to assess the impact of surgical management of endometrioma, on the outcome of assisted reproduction. Our main finding is that there was no significant difference in pregnancy rate per cycle, clinical pregnancy rate and live birth rate between women who underwent surgery for endometrioma and those who did not. Interestingly, there was a slight improvement in live birth rate but only four studies published live birth. The limitation of these data is that most of the studies on surgical management are retrospective in nature and very few publishing data on live birth rate. There is also the added limitation of variations in surgical techniques (i.e., ablation versus resection), completeness of removal of the disease, and differences in ART laboratories.

There is much controversy regarding the surgical management of endometrioma on assisted reproduction outcome. Studies have suggested that the pathophysiologic process in endometrioma formation may be different to other manifestations of endometriosis $[11,14]$.

Pre-cycle surgical management of endometrioma has been suggested to be beneficial in specific circumstances and include [1] inability to access follicles at oocyte retrieval, [2] concern that oocytes may be exposed to endometrioma fluid, which may damage oocytes, and [3] the presumption that endometrioma resection would improve IVF outcome. These will be addressed individually. First, the inability to access follicles may indeed be true for endometriomas which are larger than 4-5 cm in mean diameter. With regards to exposure to endometrioma fluid, there is no evidence to suggest this is the case. Indeed, at least one investigative team has shown that exposure of oocytes to endometrioma fluid has no impact on rates of fertilisation on early embryo development [6]. Finally, with regards to improving IVF outcome, there are two meta-analyses that have assessed the impact of endometrioma resection on IVF outcomes. Tsoumpou et al. demonstrated no significant differences in response to gonadotropin stimulation or in clinical pregnancy rates, when analyzing five studies which compared surgical resection of endometrioma to no treatment [50]. A Cochrane metaanalysis involving 312 patients by Benschop et al. confirmed that surgical management of endometrioma's resulted in no benefits for a subsequent IVF cycle [51]. Importantly, these trials are limited as they are surgical in nature, and did not control for any confounding factors with regards to differing surgical techniques (aspiration, stripping and total excision, partial resection, and ablation), endometrioma size, or laterality. Indeed, this may mean that the only indication for removing an endometrioma greater than $3 \mathrm{~cm}$ in mean diameter before IVF, as suggested by Elter and Oral, would be to treat painful symptoms or to improve ovarian access [52]. Garcia-Velasco and Somigliana suggested indications for surgical intervention that may be beneficial for assisted reproduction. Proposed Indications for Resection of a Suspected Endometrioma prior to assisted reproduction [13]:

1. rapid growth,

2. suspicious features noted on ultrasound,

3. painful symptoms that can be attributed to the mass,

4. potential for rupture in pregnancy,

5. inability to access follicles in normal ovarian tissue.

Fundamentally, it is crucial that if endometrioma resection is indicated, one must proceed conservatively to minimize any compromise of ovarian blood supply and preserve normal ovarian tissue [53].

Needless to say, there are arguments against pre-cycle treatment of endometrioma. Evidence has suggested that not only has excision of endometriomas failed to be beneficial, but surgery may indeed, be detrimental. The evidence for this statement is based on excision of stable lesions at least $3 \mathrm{~cm}$ in diameter and without worrying features [54]. Somigliana et al. reported a $53 \%$ reduction in response to gonadotrophins in ovaries that had been operated upon regardless of size of the cyst with an absence in follicular development in $13 \%$ of cases after excision of unilateral endometriomas $[36,54]$. These data are supported by other studies. Furthermore, Somigliana et al. reviewed that nine of 11 studies showed a statistically significant postoperative decline in serum anti-Mullerian hormone (AMH) levels, which was exacerbated by excision of bilateral lesions [55]. Muzii et al., in a recent meta-analysis, extracted data on 597 patients from 13 evaluated studies, and demonstrated that despite heterogeneity amongst the studies, the antral follicle count was inherently lower in the affected ovary [56]. 
Harb et al. suggest from their systematic review that the implantation and clinical pregnancy rate are reduced in women with severe endometriosis although the most important clinical outcome was live birth rate, and although a reduction of $14 \%$ in live births $(\mathrm{RR}=0.86,95 \% \mathrm{CI}$ 0.68-1.08) was observed with stage III/IV endometriosis, this did not reach statistical significance [57]. They suggest that this may be attributed to fewer reports of live birth rate in the literature, and hence weakening the power of their review to detect this outcome [57].

Furthermore, Hong et al. reported that IVF cycle outcomes including clinical pregnancy and live birth rate were not significantly different between the two groups of diminished ovarian reserve with surgery and without surgery [58]. They speculate that endometriosis-related infertility is attributed to diminished ovarian reserve and not the reduced endometrial receptivity, inferior oocyte and embryo quality [58].

Contrasting reports have shown that pre-cycle surgical intervention may be beneficial. Opøien et al. studied patients with stage I/II endometriosis from a single centre, in a retrospective trial, who underwent surgical resection or controls who underwent diagnostic laparoscopy only before IVF/ ICSI [59]. They found significantly higher clinical pregnancy (40.1 versus $29.4 \%, P=0.004)$, implantation (30.9 versus $23.9 \% ; P=0.02$ ) rates were achieved in those who underwent resection than those who underwent diagnostic laparoscopy, and live birth rate per ovum retrieval (27.7 versus $20.6 \%, P=0.04$ ) [59]. Barri et al. evaluated 825 patients with endometriosis-related infertility over a sevenyear period, and reported that overall pregnancy rates were significantly higher in patients undergoing surgical resection and then IVF in comparison to those who underwent surgery alone, IVF alone, or no treatment $(65.8,54.2,32.1$, and $11.8 \%$ ) [60]. Of note, it was unexpected that pregnancy rates from surgery alone would be so much higher than with IVF alone; however, this may be attributed to pregnancy rates being reported as cumulative. The mean time to achieve pregnancy after surgery was $11.8 \pm 12.1$ months (range 1-66 months) [60].

The lack of randomised trials regarding pre-IVF cycle surgical management of endometriosis makes it difficult to recommend this approach unless symptom relief is the primary goal.

The current endometriosis guidelines by ESHRE 2013 recommend that "In infertile women with ovarian endometrioma undergoing surgery, clinicians should perform excision of the endometrioma capsule, instead of drainage and electrocoagulation of the endometrioma wall, to increase spontaneous pregnancy rates." Hart et al. are the source quoted for this statement, but they did not examine within their study, if there is a favoured surgical approach, if any, to women undergoing fertility treatment [61].
These studies highlight that as clinicians, we need to balance the risks and benefits of pre-IVF cycle endometrioma resection given that the bulk of evidence suggests that there is no significant difference in live pregnancy rate. Patients should be counseled with regard to outcome, as well as the risks to ovarian reserve and response particularly in those who already have evidence of compromise.

\section{Conclusion}

Current evidence suggests that women with endometriosis-related infertility have similar cycle outcomes to other patients going through ART. Pre-cycle surgical management of endometrioma does not appear to be beneficial aside from achieving symptom relief, although heterogeneity amongst studies make data analysis challenging.

Endometriomas should not be resected to improve ART outcome and much evidence suggests a detrimental effect of surgery on ovarian reserve and response. The indications for surgical intervention should be limited to suspicious features, rapid growth, progressive symptoms, and an inability to aspirate follicles due to the size of the lesion. Conservative surgical approaches taking great care to avoid compromise of normal ovarian tissue and blood supply are critical. Unfortunately, the evidence is largely based on retrospective data.

It is pertinent for clinicians to assess the risks of surgical intervention on ovarian reserve prior to initiating therapy. The need for additional well-designed prospective randomised controlled trial is vital, as only one RCT had been done before. So we are relying on non-randomised data. In the world of evidence-based medicine, we should aim for the highest standard of evidence; there is a need for multi-centre RCT with live birth rate as the primary outcome to allow clinicians care for these patients.

Author contributions MNA: Data extraction and analysis, manuscript writing and review. RS: Data extraction and analysis, and manuscript review. KM and EEOs: Project conception and manuscript review. MA: Project conception, data extraction and analysis, and manuscript review.

\section{Compliance with ethical standards}

Funding No funding was needed for this work.

Conflict of interest There are no conflicts of interest.

Ethical approval This article does not contain any studies with human participants performed by any of the authors.

Open Access This article is distributed under the terms of the Creative Commons Attribution 4.0 International License (http://creativecomm ons.org/licenses/by/4.0/), which permits unrestricted use, distribution, 
and reproduction in any medium, provided you give appropriate credit to the original author(s) and the source, provide a link to the Creative Commons license, and indicate if changes were made.

\section{References}

1. Giudice LC, Kao LC (2004) Endometriosis. Lancet. 364(9447):1789-1799

2. Kennedy S, Bergqvist A, Chapron C, D'Hooghe T, Dunselman G, Saridogan E et al (2005) ESHRE guideline on the diagnosis and management of endometriosis. Hum Reprod 20(10):2698-2704. https://doi.org/10.1093/humrep/dei135

3. Macer ML, Taylor HS (2012) Endometriosis and infertility: a review of the pathogenesis and treatment of endometriosis- associated infertility. Obstet Gynecol Clin North Am 39:535-549

4. Olivennes F (2003) Results of IVF in women with endometriosis. J Gynecol Obstet Biol Reprod (Paris) 32:S45-S47

5. Cahill DJ, Wardle PG, Harlow CR, Hull MG (1996) Effect of progestogen therapy on follicular development, related hormone concentrations and fertilization in vitro in unstimulated cycles and unexplained and endometriosis-associated infertility. Hum Reprod $11: 647-650$

6. Khamsi F, Yavas Y, Lacanna IC, Roberge S, Endman M, Wong JC (2001) Exposure of human oocytes to endometrioma fluid does not alter fertilization or early embryo development. J Assist Reprod Genet 18:106-109

7. Dmowski WP, Rana N, Michalowska J, Friberg J, Papierniak C, el-Roeiy A (1995) The effect of endometriosis, its stage and activity, and of autoantibodies on in vitro fertilization and embryo transfer success rates. Fertil Steril 63:555-562

8. Pellicer A, Valbuena D, Bauset C, Albert C, Bonilla-Musoles F, Remohi J et al (1998) The follicular endocrine environment in stimulated cycles of women with endometriosis: steroid levels and embryo quality. Fertil Steril 69:1135-1141

9. Matalliotakis IM, Cakmak H, Mahutte N, Fragouli Y, Arici A, Sakkas D (2007) Women with advanced-stage endometriosis and previous surgery respond less well to gonadotropin stimulation, but have similar IVF implantation and delivery rates compared with women with tubal factor infertility. Fertil Steril $88: 1568-1572$

10. Hughesdon PE (1957) The structure of endometrial cysts of the ovary. J Obst Gynaecol Br Empire 64(4):481-487

11. Brosens I, Puttemans P, Gordts S, Campo R, Gordts S, Benagiano G (2013) Early stage management of ovarian endometrioma to prevent infertility. Facts Views Vis ObGyn 5(4):309-314

12. Alborzi S, Keramati P, Younesi M, Samsami A, Dadras N (2014) The impact of laparoscopic cystectomy on ovarian reserve in patients with unilateral and bilateral endometriomas. Fertil Steril 101(2):427-434

13. Garcia-Velasco A, Somigliana E (2009) Management of endometriomas in women requiring IVF: to touch or not to touch. Hum Reprod 24(3):496-501

14. Sanchez AM, Viganò $P$, Somigliana E, Panina-Bordigno $P$, Vercellini P, Candiani M (2014) The distinguishing cellular and molecular features of the endometriotic ovarian cyst: from pathophysiology to the potential endometrioma-mediated damage to the ovary. Human Reproduction Update 20(2):217-230

15. Pabuccu R, Onalan G, Goktolga U, Kucuk T, Orhon E, Ceyhan $\mathrm{T}$ (2004) Aspiration of ovarian endometriomas before intracytoplasmic sperm injection. Fertil Steril 82:705-711

16. Ragni G, Somigliana E, Benedetti F, Paffoni A, Vegetti W, Restelli L et al (2005) Damage to ovarian reserve associated with laparoscopic excision of endometriomas: a quantitative rather than a qualitative injury. Am J Obstet Gynecol 193:1908-1914
17. Marconi G, Vilela M, Quintana R, Sueldo C (2002) Laparoscopic ovarian cystectomy of endometriomas does not affect the ovarian response to gonadotrophin stimulation. Fertil Steril 78:876-878

18. Dong X, Wang R, Zheng Y, Xiong T, Lian X, Huang B, Zhang $H$ (2014) Surgical treatment of endometrioma does not increase clinical pregnancy rate or live birth/ongoing pregnancy rate after fresh IVF/IVSI treatment. Am J Transl Res 6(2):163-168

19. Wong BC, Gillman NC, Oehninger S, Gibbons WE, Stadtmauer LA (2004) Results of in vitro fertilization in patients with endometriomas: is surgical removal beneficial? Am J Obstet Gynecol 191:598-607

20. Pabuccu R, Onalan G, Kaya C (2007) GnRH agonist and antagonist protocols for stage I-II endometriosis and endometrioma in in vitro fertilization/intracytoplasmic sperm injection cycles. Fertil Steril 88:832-839

21. Suganuma N, Wakahara Y, Ishida D, Asano M, Kitagawa T, Katsumata Y et al (2002) Pretreatment for ovarian endometrial cyst before in vitro fertilization. Gynecol Obstet Invest 54(Suppl. 1):36-42

22. Takuma N, Sengoku K, Pan B, Wada K, Yamauchi T, Miyamoto $T$ et al (2002) Laparoscopic treatment of endometrioma-associated infertility and pregnancy outcome. Gynecol Obstet Invest 54:30-35

23. Ho HY, Lee RK, Hwu YM, Lin MH, Su JT, Tsai YC (2002) Poor response of ovaries with endometrioma previously treated with cystectomy to controlled ovarian hyperstimulation. J Assist Reprod Genet 19:507-511

24. Duru NK, Dede M, Acikel CH, Keskin U, Fidan U, Baser I (2007) Outcome of in vitro fertilization and ovarian response after endometrioma stripping at laparoscopy and laparotomy. J Reprod Med 52:805-809

25. Wyns C, Donnez J (2003) Laser vaporization of ovarian endometriomas: the impact on the response to gonadotrophin stimulation. Gynecol Obstet Fertil 31:337-342

26. Somigliana E, Arnoldi M, Benaglia L, Iemmello R, Nicolosi AE, Ragni G (2008) IVF-ICSI outcome in women operated on for bilateral endometriomas. Hum Reprod 23(7):1526-1530

27. Bongioanni F, Revelli A, Gennarelli G, Guidetti D, Delle Piane LD, Holte J (2011) Ovarian endometriomas and IVF: a retrospective case-control study. Reprod Biol Endocrinol 17(9):81

28. Lee KH, Kim CH, Lee YJ, Kim SH, Chae HD, Kang BM (2014) Surgical resection or aspiration with ethanol sclerotherapy of endometrioma before in vitro fertilization in infertilie women with endometrioma. Obstet Gynecol Sci 57(4):297-303

29. Garcia-Velasco JA, Mahutte NG, Corona J, Zuniga V, Giles J, Arici A et al (2004) Removal of endometriomas before in vitro fertilization does not improve fertility outcomes: a matched, casecontrol study. Fertil Steril 81:1194-1197

30. Tinkanen H, Kujansuu E (2000) In vitro fertilization in patients with ovarian endometriomas. Acta Obstet Gynecol Scand 79:119-122

31. Demirol A, Guven S, Baykal C, Gurgan T (2005) Effect of endometrioma cystectomy on IVF outcome: a prospective randomised study. Reprod Biomed Online 12:639-643

32. Harada M, Takahashi N, Hirata T, Koga K, Fujii T (2015) Osuga Y Laparoscopic excision of ovarian endometrioma does not exert a qualitative effect on ovarian function: insights from in vitro fertilization and single embryo transfer cycles. J Assist Reprod Genet 32(5):685-689

33. Benaglia L, Bermejo A, Somigliana E, Scarduelli C, Ragni G, Fedele L, Garcia-Velasco JA (2012) 9. Pregnancy outcome in women with endometriomas achieving pregnancy through IVF. Hum Reprod. 27(6):1663-1667

34. Nakagawa K, Ohgi S, Kojima R, Sugawara K, Ito M, Horikawa T, Irahara M, Saito H (2007) Impact of laparoscopic cystectomy 
on fecundity of infertility patients with ovarian endometrioma. J Obstet Gynaecol Res 33(5):671-676

35. Shimizu Y, Takashima A, Takahashi K, Kita N, Fujiwara M, Murakami T (2010) Long-term outcome, including pregnancy rate, recurrence rate and ovarian reserve, after laparoscopic laser ablation surgery in infertile women with endometrioma. J Obstet Gynaecol Res 36(1):115-118

36. Benaglia L, Somigliana E, Vighi V, Ragni G, Vercellini P, Fedele L (2010) Rate of severe ovarian damage following surgery for endometriomas. Hum Reprod 25(3):678-682

37. Suzuki T, Izumi S, Matsubayashi H, Awaji H, Yoshikata K, Makino T (2005) Impact of ovarian endometrioma on oocytes and pregnancy outcome in in vitro fertilization. Fertil Steril 83(4):908-913

38. Oppenheimer A, Ballester M, Mathieu d'Argent E, Morcel K, Antoine JM, Daraï E (2013) Pregnancy rate after first intra cytoplasmic sperm injection-in vitro fertilisation cycle in patients with endometrioma with or without deep infiltrating endometriosis. Int J Fertil Steril 7(3):207-216

39. Ashrafi M, Fakheri T, Kiani K, Sadeghi M, Akhoond MR (2014) Impact of the endometrioma on ovarian response and pregnancy rate in in vitro fertilization cycles. Int J Fert Sterril 8(1):29-34

40. Almog B, Shehata F, Sheizaf B, Tan SL, Tulandi T (2011) Effects of ovarian endometrioma on the number of oocytes retrieved for in vitro fertilization. Fertil Steril 95(2):525-571

41. Duru NK, Dede M, Acikel CH, Keskin U, Fidan U, Baser I (2007) Outcome of in vitro fertilization and ovarian response after endometrioma stripping at laparoscopy and laparotomy. J Reprod Med 52(9):805-809

42. Alborzi S, Momtahan M, Parsanezhad ME, Dehbashi S, Zolghadri J, Alborzi S (2004) A prospective, randomised study comparing laparoscopic ovarian cystectomy versus fenestration and coagulation in patients with endometriomas. Fertil Steril 82(6):1633-1637

43. Takashima A, Takeshita N, Otaka K, Kinoshita T (2013) Effects of bipolar electrocoagulation versus suture after laparoscopic excision of ovarian endometrioma on the ovarian reserve and outcome of in vitro fertilization. J Obstet Gynaecol Res 39(7):1246-1252

44. Alborzi S, Ravanbakhsh R, Parsanezhad ME, Alborzi M, Alborzi S, Dehbashi S (2007) A comparison of follicular response of ovaries to ovulation induction after laparoscopic ovarian cystectomy or fenestration and coagulation versus normal ovaries in patients with endometrioma. Fertil Steril 88(2):507-509

45. Beretta P, Franchi M, Ghezzi F, Busacca M, Zupi E, Bolis P (1998) Randomised clinical trial of two laparoscopic treatments of endometriomas: cystectomy versus drainage and coagulation. Fertil Steril 70(6):1176-1180

46. Park H, Kim CH, Kim EY, Moon JW, Kim SH, Chae HD, Kang BM (2015) Effect of second-line surgery on in vitro fertilization outcome in infertile women with ovarian endometrioma recurrence after primary conservative surgery for moderate to severeendometriosis. Obstet Gynecol Sci 58(6):481-486

47. Yu HT, Huang HY, Lee CL, Soong YK, Wang CJ (2015) Side of ovarian endometrioma does not affect the outcome of in vitro fertilization/intracytoplasmic sperm injection in infertile women after laparoscopic cystectomy. J Obstet Gynaecol Res 41(5):717-721

48. Li Z, Zhang HY, Zhu YJ, Hu YJ, Qu PP (2014) Randomised study comparing the side effects and hormonal status of triptorelin and leuprorelin following conservative laparoscopic surgery for ovarian endometriosis in Chinese women. Eur J Obstet Gynecol Reprod Biol 183:164-168

49. Roustan A, Perrin J, Debals-Gonthier M, Paulmyer-Lacroix O, Agostini A, Courbiere B (2015) Surgical diminished ovarian reserve after endometrioma cystectomy versus idiopathic DOR: comparison of in vitro fertilization outcome. Hum Reprod 30(4):840-847
50. Tsoumpou I, Kyrgiou M, Gelbaya TA, Nardo LG (2009) The effect of surgical treatment for endometrioma on in vitro fertilization outcomes: a systematic review and meta-analysis. Fertil Steril 92(1):75-87

51. Benschop L, Farquhar C, van der Poel N, Heineman MJ (2010) Interventions for women with endometrioma prior to assisted reproductive technology. Cochrane Database Syst Rev. 11:008571

52. Elter K, Oral E (2014) Surgical treatment before assisted reproductive technologies. Semin Reprod Med 32(4):253-261

53. Tang Y, Chen SL, Chen X, He YX, Ye DS, Guo W, Zheng HY, Yang XH (2013) Ovarian damage after laparoscopic endometrioma excision might be related to the size of cyst. Fertil Steril 100(2):464-469

54. Somigliana E, Ragni G, Benedetti F, Borroni R, Vegetti W, Crosignani PG (2003) Does laparoscopic excision of endometriotic ovarian cysts significantly affect ovarian reserve? Insights from IVF cycles. Hum Reprod 18:2450-2453

55. Somigliana E, Berlanda N, Benaglia L, Vigano P, Vercellini P, Fedele L (2012) Surgical excision of endometriomas and ovarian reserve: a systematic review on serum antimullerian hormone level modifications. Fertil Steril 98(6):1531-1538

56. Muzii L, di Tucci C, di Feliciantonio M, Marchetti C, Perniola G, Benedetti Panici P (2014) The effect of surgery for endometrioma on ovarian reserve evaluated by antral follicle count: a systematic review and meta-analysis. Hum Reprod 29(10):2190-2198

57. Harb HM, Gallos ID, Chu J, Harb M, Coomarasamy A (2013) The effect of endometriosis on in vitro fertilisation outcome: a systematic review and meta-analysis. BJOG 120(11):1308-1320

58. Hong SB, Lee NR, Kim SK, Kim H, Jee BC, Suh CS, Kim SH, Choi YM (2017) In vitro fertilization outcomes in women with surgery induced diminished ovarian reserve after endometrioma operation: comparison with diminished ovarian reserve without ovarian surgery. Obstet Gynecol Sci 60(1):63-68

59. Opøien HK, Fedorcsak P, Byholm T, Tanbo T (2011) Complete surgical removal of minimal and mild endometriosis improves outcome of subsequent IVF/ICSI treatment. Reprod BioMed Online 23(3):389-395

60. Barri PN, Coroleu B, Tur R, Barri-Soldevila PN, Rodríguez I (2010) Endometriosis-associated infertility: surgery and IVF, a comprehensive therapeutic approach. Reprod BioMed Online 21(2):179-185

61. Hart RJ, Hickey M, Maouris P, Buckett W (2008) Excisional surgery versus ablative surgery for ovarian endometriomata. Cochrane Database Syst Rev (2):CD004992. https://doi. org/10.1002/14651858.CD004992.pub3

\section{Studies excluded from meta- analysis}

62. Aflatoonian A, Rahmani E, Rahsepar M (2013) Assessing the efficacy of aspiration and ethanol injection in recurrent endometrioma before IVF cycle: a randomised clinical trial. Iran J Reprod Med 11(3):179-184

63. Esinler I, Bozdag G, Aybar F, Bayar U, Yaradi H (2006) Outcome of in vitro fertilization/intracytoplasmic sperm injection after laparoscopic cystectomy for endometriomas. Fertil Steril 85:1730-1735

64. Kahyaoglu S, Ertas E, Kahyaoglu I, Mollamahmutoglu L, Batioglu S (2008) Does laparoscopic cystectomy and cauterization of endometriomas greater than $3 \mathrm{~cm}$ diminish ovarian response to controlled ovarian hyperstimulation during IVF-ET? A casecontrol study. J Obstet Gynaecol Res 34(6):1010-1013

65. Loh FH, Tan AT, Kumar J, Ng SC (1999) Ovarian response after laparoscopic ovarian cystectomy for endometriotic cysts in 132 monitored cycles. Fertil Steril 72:316-321 
66. Loo TC, Lin M, Chen SH, Chung MT, Tang HH, Lin LY et al (2005) Endometrioma undergoing laparoscopic ovarian cystectomy: its influence on the outcome of in vitro fertilization and embryo transfer (IVF-ET). J Assist Reprod Genet 22:329-333

67. Matalliotakis I, Cakmak H, Mahutte N, Fragouli Y, Arici A, Sakkas D (2007) Women with advanced-stage endometriosis and previous surgery respond less well to gonadotrophin stimulation, but have similar IVF implantation and delivery rates compared with women with tubal factor infertility. Fertil Steril 88:1568-1572
68. Nargund G, Cheng WC, Parsons J (1995) The impact of ovarian cystectomy on ovarian response to stimulation during in vitro fertilization cycles. Hum Reprod 11:81-83

69. Wu MH, Tsai SJ, Pan HA, Hsiao KY, Chang FM (2003) Threedimensional power Doppler imaging of ovarian stromal blood flow in women with endometriosis undergoing in vitro fertilization. Ultrasound Obstet Gynecol 21:480-485 